Recebido em 28 de janeiro de 2015 / Aprovado em 02 de abril de 2015.

Editor Científico: Dr. Geysler Rogis Flor Bertolini

Processo de Avaliação: Double Blind Review

E-ISSN: 2359-5876

https://doi.org/10.5935/2359-5876.20150007

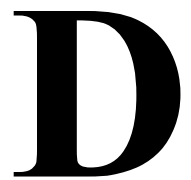

\title{
ESEMPENHO FISCAL DOS MUNICIPIOS PARANAENSES E SEUS DETERMINANTES: UMA ANÁLISE ECONOMÉTRICA PARA O PERÍODO DE 2001 A 2010
}

\author{
Carla Beatriz Rachwal \\ Bacharel em Ciências Econômicas pela Universidade Estadual do Oeste do Paraná - \\ UNIOESTE, Campus de Francisco Beltrão, Brasil \\ cbr_ac@hotmail.com
}

Gilmar Ribeiro de Mel

Doutor em Ciências Contábeis pela Universidade de São Paulo - USP, Brasil Professor Adjunto do Centro de Ciências Sociais Aplicadas e do Mestrado em Gestão e Desenvolvimento Regional, da Universidade Estadual do Oeste do Paraná (Unioeste), Campus de Francisco Beltrão, Brasil gilmarribeirodemello@gmail.com

\begin{abstract}
RESUMO
O objetivo deste estudo é analisar a eficiência tributária própria dos municípios paranaenses e, por conseguinte, diminuição de sua dependência dos repasses do Governo Federal. O trabalho abrangeu 349 municípios paranaenses no período de 2001 á 2010. Primeiramente foi calculado o Índice de Desempenho Tributário e Econômico (IDTE), e na sequência foi realizado um cálculo estatístico de dados em painel, verificando quais variáveis melhor explicam maiores IDTEs. Concluiu-se que para mais $70 \%$ dos municípios paranaenses o IDTE é menor que uma unidade, comprovando que o repasse do Fundo de Participação dos Municípios (FPM) supera as receitas tributárias próprias e a cota-parte do Imposto sobre a Circulação de Mercadorias e Serviços (ICMS). Os municípios com os maiores IDTEs, possuem algumas particularidades, Araucária e Curitiba apresentam os melhores indicadores.
\end{abstract}

Palavras-chave: Eficiência Tributária; Finanças Públicas; Municípios Paranaenses. 
FISCAL PERFORMANCE OF MUNICIPALITIES PARANAENSES AND ITS DETERMINANTS: AN ECONOMETRIC ANALYSIS FOR THE PERIOD 2001 TO 2010

\begin{abstract}
This study aimed to analyze the own tax efficiency of municipal districts and therefore decrease their dependence on transfers from the Federal Government. The study covered 349 municipalities paranaenses from 2001 to 2010. First Tax and Economic Performance Index (TEPI) was calculated, and following a statistical calculation of panel data was performed by checking which variables best explain higher TEPI. It was concluded that for more than $70 \%$ of the municipalities of Paraná TEPI is less than one unit, stating that the transfer of Background of Participation of Local (BPL) outperforms own tax revenues and quota-share of the Tax on Movement of Goods and Services (TMGS). The municipalities with the highest TEPI, have some peculiarities, Araucaria and Curitiba have the best indicators.
\end{abstract}

Keywords: Tax Efficiency; Public Finance; Municipalities Paranaenses. 


\section{INTRODUÇÃO}

A Lei de Responsabilidade Fiscal (Lei Complementar 101, de 04 de maio de 2000), advinda do programa de ajuste fiscal desenvolvido pelo governo federal no final da década de 90, institui novo paradigma de gestão pública concluindo que o Estado não pode gastar mais do que arrecada, forçando os governos a se tornarem mais eficientes na sua administração tributária. Este trabalho busca ampliar o conhecimento sobre as particularidades da administração tributária municipal, visualizando de maneira mais aprofundada as dificuldades enfrentadas pelos governos locais na arrecadação dos tributos de sua competência.

Segundo o IPEA (2009), há 2.693 Municípios, com até 10 mil habitantes, que arrecadam até $4 \%$ de suas despesas, enquanto que os Municípios com população de $10 \mathrm{mil} \mathrm{a} 20 \mathrm{mil}$ arrecadam $8,9 \%$, passando para $13 \%$ nos Municípios com população entre 20 mil e 50 mil. Para o Instituto a ineficiência da gestão administrativa é causa determinante do mau desempenho arrecadatório. O IPTU (Imposto Predial e Territorial Urbano) é o principal responsável pela baixa arrecadação, devido a seu valor imobiliário ser regressivo e cadastro incompleto, acolá os Municípios que isentam seus contribuintes do imposto.

Para Riani (1986), os impostos de competência municipal apresentam potencial variado. Nos Municípios mais pobres, a baixa arrecadação do IPTU e ISSQN (Imposto Sobre Serviço de Qualquer Natureza) os tornam mais dependentes dos repasses federais e estaduais. E mesmo nos casos dos Municípios com adequada arrecadação as demandas sempre maiores por bens e serviços públicos exigem complementação através destas transferências.

O Indicador de Desempenho Tributário e Econômico (IDTE), criado para analisar a eficiência dos Municípios em dado intervalo de tempo, vem tentar visualizar as deficiências de cada Município paranaense, objetivando a redução da dependência dos repasses pelo conhecimento das variáveis com impacto preponderante para alcançar melhores IDTEs para estes Municípios (OLIVEIRA et al., 1998).

Assim sendo, o questionamento que se faz é quais variáveis econômicas dos Municípios Paranaenses podem melhor explicar a capacidade própria de sua geração de recursos?

O presente trabalho procura responder a questão de pesquisa descrita, com o objetivo de analisar a eficiência dos Municípios Paranaenses na geração de receitas próprias e, por conseguinte, redução de sua dependência dos repasses do Governo Federal.

\section{REVISÃO DE LITERATURA}

\subsection{REGIME TRIBUTÁRIO BRASILEIRO}

A Constituição de 1988 eleva os Municípios a membros da Federação, concedendo os mesmos direitos e deveres dos Estados. Os Municípios passam a ter maior autonomia com menor controle do Estado. Em meados dos anos 90 ocorre a descentralização fiscal, momento que se sente os efeitos da constituição de 1988. O aumento da participação dos Estados e Municípios passa de $30 \%$ para $44 \%$, sendo os Municípios os mais beneficiados, com elevação de $17 \%$ em 2000. O repasse maior para esses entes remete as autoridades federais maior dependência das contribuições sociais, tornando indesejável a qualidade do sistema tributário brasileiro (REZENDE, 2001).

O orçamento dos Estados e Município fora afetado devido ao baixo crescimento econômico e ao custo de implantação de uma disciplina fiscal. Os Municípios foram forçados a aumentar o esforço fiscal devido as maiores demandas por gastos sociais. Mesmo com o aumento de recursos injetados nas atividades sociais, através dos Estados e Municípios, os maiores volumes para melhoria da qualidade de vida provém das contribuições sociais arrecadados pelo Governo Federal (Ibid.).

A Constituição Federal de 1988 institucionalizou a descentralização fiscal, dando maior autonomia aos governos estaduais, conforme pode ser observado por Oliveira (1991, p. 31): "na esfera político fiscal, o processo de democratização teve como ponto de apoio o aumento da participação dos governos locais na receita disponível. As competências tributárias de cada nível foram meticulosamente descriminadas no texto constitucional."

Não obstante, Torres (2003, p. 364), observa que:

Os Municípios, a exemplo dos Estados e da União, têm a competência dos tributos denominados de competência comum, que são as taxas e as contribuições de melhoria. A competência comum consiste na possibilidade de cada ente político impor os mesmos tributos, guardando, entretanto, o vinculo entre o tributo e o serviço prestado ou a atividade exercida. A competência comum se restringe aos tributos contraprestacionais (taxas e contribuição de melhoria), donde se segue que é devido ao ente que houver entregue a prestação.

É por meio da tributação que os entes procuram obter recursos da coletividade para suprir as necessidades da sociedade. O cenário político, 
econômico e social de cada país ou região fará com que haja alterações no sistema tributário, visto que, suas peculiaridades refletem no mesmo. Mesmo com suas diferenças o sistema tributário torna-se a principal fonte dos recursos públicos no sistema capitalista. Ajustando a distribuição de renda e tornando possível o desempenho das atividades públicas. O sistema tributário é o principal instrumento de política fiscal do governo, varias análises mostram a maneira mais eficiente de funcionamento.

Segundo Riani (1986, p. 78), espera-se que o sistema tributário siga pontos básicos:

- o primeiro deveria se o de se obterem receitas para financiar os serviços públicos;

- cada indivíduo deveria ser taxado de acordo com sua habilidade para pagar;

- os tributos devem ser universais, impostos sem distinção á indivíduos em situações similares;

- os tributos deveriam ser escolhidos de forma a minimizar sua interferência no sistema de mercado, a fim de não torná-lo mais ineficiente.

Segundo o autor, o sistema tributário deveria ser o mais justo possível. Devido a dificuldade de alcançar tal justiça, busca-se a aplicação do princípio dos benefícios e da habilidade de pagamento.

\subsection{RECEITAS E DESPESAS MUNICIPAIS}

Do somatório das receitas municipais, serão analisadas somente as tributárias, provenientes da arrecadação de impostos. Inseridos na Constituição Federal de 1988, em seu artigo 156, são eles:

I - imposto sobre a propriedade predial e territorial urbana;

II - imposto sobre transmissão, inter vivos, a qualquer titulo, por ato oneroso, de bens imóveis, por natureza ou acessão física, e de direitos reais sobre imóveis, exceto os de garantia, bem como acessão de direitos a sua aquisição;

III - imposto sobre serviço de qualquer natureza, não compreendidos no artigo 155 , II, definidos em Lei Complementar (BRASIL, 1988).

As receitas provenientes do Imposto sobre Propriedade Territorial Urbana (IPTU) é de competência exclusiva dos Municípios. A arrecadação do IPTU no Brasil é baixa, havendo ampla margem de incremento, podendo tornar-se importante fonte de arrecadação dos Municípios um imposto de característica visível e real, onde o poder local tem maior facilidade de conhecimento do espaço urbano (CARVALHO JR., 2006).

Em relação ao Imposto sobre a Transferência de Bens Imóveis (ITBI), segundo Costa (1999, p. 248), “o imposto sobre Transmissão inter vivos, é tributo novo, criado pela Constituição de 1988, no artigo 156, II, tendo origem do anterior imposto estadual sobre transmissão inter vivos e causa mortis. No caso da transmissão ser por herança ("causa mortis"), o ITBI não é cobrado; ao invés dele, será cobrado o ITCMD (Imposto Transmissão Causa Mortis e Doações), que passa a ser imposto de competência do Estado.

O imposto compete ao Município e incide nas transações imobiliárias pela aplicação de uma alíquota sobre o valor venal do imóvel, o qual é atribuído pelo setor tributário de cada Município. Até a Constituição de 1988, esse imposto era de competência do Estado, sendo repassado $50 \%$ do valor arrecado para o Município sede do bem imóvel, com a mudança de competência, o Município passou a se empenhar na fiscalização do valor usado nas transações e com exigibilidade do prévio pagamento para escrituração do bem.

Outro imposto de responsabilidade dos Municípios é o ISSQN, Imposto sobre Serviços de qualquer Natureza. Segundo Costa (1999, p. 249), "distingue-se serviço (ISS) a prestação de fazer, de produto industrializado (IPI), que é resultado da produção física ou mental, e de mercadoria (ICMS), que são as coisas moveis objeto de comércio".

Além dos impostos citados, têm-se as taxas de iluminação pública, coleta de lixo e alvará de funcionamento, e a contribuição de melhoria, cobrada por obras realizadas pelo poder municipal.

Segundo Cepam (1997, p. 92): as receitas de serviços são inúmeras e vão depender das estrutura administrativa de cada Município. Assim, podem ser instituídas as taxas de limpeza pública, de pavimentação, de remoção de lixo, de conservação de vias e logradouros, de iluminação pública, de conservação de estradas, entre outras.

A municipalidade não visa lucro através da cobrança de receitas de serviço, mas não deve suportar déficits. Conforme entendimento de Torres (2003, p. 362): “taxas de serviço é um tributo contraprestacional, posto que vinculado a uma prestação estatal especifica em favor do contribuinte é cobrada pela prestação de serviços público ou pelo exercício do poder de polícia."

As transferências governamentais sejam elas federais ou estaduais, objetivam compensar as concentrações de arrecadação em níveis elevados de governo, devolvendo a cada base tributária o volume de sua arrecadação. A função de 
arrecadação é praticada pelo nível superior de governo mas a jurisdição local de onde ocorreu o fato gerador é detentora do mesmo, caráter devolutivo. As transferências também podem ser de caráter redistributivo, nesse caso os níveis superiores de governo buscam reduzir as desigualdades entre regiões. O FPM enquadra-se nessa categoria. E por fim as transferências com finalidade de viabilização de políticas de interesse nacional (GASPARINI; MELO, 2004).

Aos repasses governamentais, seja estado ou federação, o que se visualiza em vários casos e principalmente em municípios de comunidades com baixa instrução e de elevada dependência desses repasses localiza-se os maiores números de corrupção, ou seja, a má aplicação das transferências, fraudes e irregularidades. $\mathrm{O}$ cuidado deve ser no sentido de não se perder eficiência em busca de receita própria.

Nesse sentido deve ser analisada a eficiência dos gastos públicos, a eficiência da arrecadação tributária e a necessidade de serviços públicos municipais, buscando maior equilíbrio socioeconômico entre os entes, fortalecendo a gestão municipal eficiente. As verbas oriundas de repasses não devem influenciar na alocação de receitas próprias. Cada município deve buscar maior arrecadação própria, independente dos recebimentos intergovernamentais (GASPARINI e MELO, 2004).

Para Oliveira (1998),

As transferências estaduais são representadas, principalmente, pela cota-parte $(25 \%)$ do imposto sobre Circulação de Mercadorias e Serviços (ICMS), mas também pelos repasses de $50 \%$ do Imposto sobre Circulação de Veículos Automotores (IPVA), alem de outras, como $50 \%$ das multas de IPVA, $25 \%$ das multas do ICMS e $25 \%$ da divida ativa tributaria. federais:

Já no que se refere às transferências

$$
\begin{aligned}
& \begin{array}{l}
\text { Advêm do repasse de } \\
\text { Imposto } 22,5 \% \text { do } \\
\text { sobre }
\end{array} \\
& \text { Industrializados (IPI) e de } 22,5 \% \text { do } \\
& \text { Imposto de Renda (IR), através do } \\
& \text { Fundo de Participação dos Municípios } \\
& \text { (FPM). A União repassa também } 50 \% \\
& \text { do Imposto Territorial Rural (ITR), o } \\
& \text { imposto retido na fonte do } \\
& \text { funcionalismo municipal e } 2,5 \% \text { do IPI } \\
& \text { via participação no Fundo de } \\
& \text { Compensação pela exportação de } \\
& \text { Produtos Industrializados, ou Fundo de } \\
& \text { Exportação (FPEX) (Ibid.). } \\
& \text { Entretanto, o Decreto n }{ }^{\circ} \text { 6.433, de } 15 \text { de }
\end{aligned}
$$
abril de 2008, o qual institui comitê gestor do imposto e do Imposto Sobre Propriedade Territorial Rural - CGITR, com a competência de arranjar a opção de convênio entre União e Municípios com efeito de delegar atribuições de fiscalização, lançamento e cobrança do ITR, desde que cumpridas exigências pré estabelecidas e com isso passam a receber a totalidade do imposto,ou seja, de $50 \%$ para $100 \%$. Para tanto seja necessário os seguintes requisitos:

I - protocolar termo de opção;

II - cumprimento dos requisitos e condições necessárias.

As transferências de FPM e de ICMS são destaque devido ao seu grau de importância na composição das receitas municipais. O nível de dependência mostra o potencial econômico-fiscal dos Municípios. O FPM é determinado pelo número de população existente e o ICMS determinado principalmente pelo Valor Adicionado Fiscal (VAF), vinculado ao potencial econômico dos Municípios.

Nos Municípios menores, com base econômica mais frágil, o Fundo de Participação dos Municípios - FPM é a fonte mais importante, já nos Municípios mais desenvolvidos, a mais importante é a quota-parte do ICMS.

No entendimento do Cepam (1997, p. 9798):
isso ocorre porque o princípio que norteia a distribuição do FPM é o redistributivo, ou seja, são repassados maiores montantes de recursos para os Municípios mais carentes. Já em relação à quota-parte do ICMS, o princípio de distribuição dos recursos é o compensatório, isto é, fazer retornar ao Município os recursos tributários nele gerados.

Todavia, é o retorno do Fundo de Participação dos Municípios - FPM na arrecadação do ICMS que garante a sobrevivência da maior parte das unidades emancipadas, e dos Municípios de pequeno porte emancipados há mais tempo.

\subsection{O INDICADOR DO DESEMPENHO TRIBUTÁRIO E ECONÔMICO (IDTE)}

De acordo com Oliveira (1998), a diversidade de estágios de certas economias torna possível construir um indicador que mensure os níveis e a estrutura de arrecadação tributária e a atividade produtiva e obtenha o nível de desenvolvimento da economia de uma dada região ou país. Mostrando com isso, que em economias menos desenvolvidas, com renda per capita e produtividade baixa, a variação desse indicador é menor. Evidenciando a necessidade de bases 
tributárias mais consistentes, originando grupo de países/regiões/localidades menos dispersas. Desenvolvendo políticas para minimizar as diferenças dessas regiões e torná-las eficientes naquilo que se apresente como maior e melhor atividade econômica.

A partir desse conhecimento criou-se o Indicador do Desempenho Tributário e Econômico (IDTE) para os Municípios Mineiros. Segundo Oliveira (1998), o IDTE, ao mesmo tempo em que permite a reunião de Municípios de acordo com estágio de desempenho Tributário e Econômico em que se encontram, representa um esforço de sintetizar, em um único indicador, o grau de suficiência fiscal dos Municípios mineiros no ano de 1996.

No referido estudo foram analisadas somente as receitas de maior relevância, ou seja, aquelas produto de sua base econômica, demonstrando seu grau de suficiência fiscal. Inserem-se nesse contexto, as Receitas Tributarias Própria (RTP) e as Transferências do Imposto Sobre Circulação de Mercadorias e Serviços (TICMS), repassadas do Estado para os Municípios. Embora seja uma transferência, a TICMS, inclusa no modelo é justificada por ser o valor agregado de suas bases econômicas. Já as Transferências do Fundo de Participação dos Municípios (TFPM) advindas do Governo Federal são mensuradas pelo critério populacional para os Municípios do interior, independente de seu dinamismo econômico. Municípios mais dependentes das TFPM caracterizam-se por economias frágeis e menos desenvolvidas diferentemente dos mais desenvolvidos, onde predominam a RTP e as TICMS.

Dadas essas características das receitas tributarias própria e ou das transferências oriundas do Estado ou da União, chegou a seguinte formula:
IDTE = (RTP + TICMS $) /$ TFPM. (1)

Tem-se seguinte classificação:

- IDTE < 1, Município com baixo nível de desempenho tributário e econômico, suas receitas mais significativas advêm das transferências FPM, não vinculadas a sua base econômica;

- IDTE > 1, Município com maior desempenho tributário e econômico, receitas tributarias próprias são mais significativas.

-IDTE $=1$, mostra que o Município depende em igual nível das suas receitas próprias quanto das transferências oriundas do FPM (TFPM).

A avaliação do IDTE (Índice de Desempenho Tributário e Econômico) dos Municípios Paranaenses baseou-se nos dados de 349 municípios para um período de 2001 á 2010. A inexistência de dados para todos os municípios nesse período, fez com que 50 deles não fizessem parte da amostra. O cálculo se deu por ano, tornando possível uma comparação da evolução do indicador, ou seja, mostrando a perda ou ganho na arrecadação, mensurada em relação a sua grandeza e eficiência econômica, em comparação aos valores arrecadados por meio do FPM (Fundo de Participação dos Municípios).

Dessa forma o indicador possibilita verificar o quanto o município é dependente da transferência de recurso aqui em questão (FPM), bem como analisar a evolução ano a ano das receitas tributárias próprias de cada município, já que o IDTE tem em seu numerador a soma de todas as suas receitas próprias as quais tem o poder de legislar, mais a sua quota-parte de ICMS e no seu denominador os repasses oriundos do governo federal por meio do FPM. A figura a seguir mostra a Evolução do Indicador de Desempeno Tributário e Econômico para os municípios Paranaenses no período 2001 á 2010.

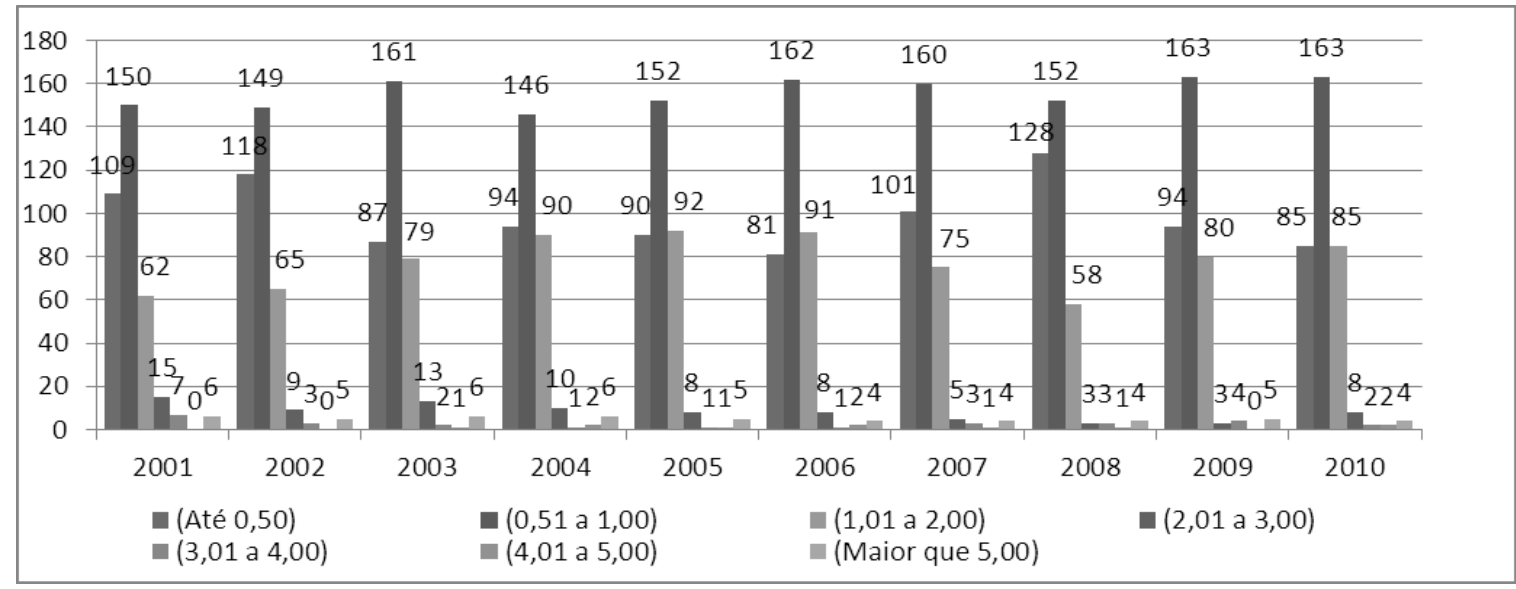

Figura 1 - Evolução do Indicador do Desempenho Tributário e Econômico PR.

Fonte: Elaboração própria a partir dos dados coletados na Secretaria do Tesouro Nacional. 
Ao analisar o indicador (IDTE), verificouse uma evolução no ano de 2003 para alguns Municípios Paranaenses. Que passam da primeira classe $(0-0,50)$ para a terceira classe $(1,01-2,00)$, permanece esse acréscimo para os anos subsequentes, mas em 2007 verifica- se uma redução e em 2009 e 2010 uma nova evolução do indicador, mostrando com isso que o ganho de Desempenho Tributário e Econômico não se dá de uma forma sustentável. As crises ocorridas no período também podem justificar o baixo desempenho, já que as variáveis econômicas utilizadas são diretamente afetadas.

Do total dos municípios aqui analisados, quando somadas as duas primeiras classes do gráfico de cada ano onde o IDTE corresponde a até uma unidade, tem-se de 70 a $80 \%$ dos municípios, ou seja, de 240 a 280 municípios paranaenses que somando suas receitas tributarias próprias mais á cota-parte ICMS não chegam a alcançar o valor recebido pelo FPM. E são esses municípios que são beneficiados pelas regras do FPM, que recebem parte das rendas que são geradas em municípios que possuem maior dinamismo econômico.

Da terceira classe em diante, onde o IDTE é de (1,01 e 2,00), encontram-se os municípios dos quais a soma das transferências da cota-parte ICMS e suas próprias receitas ultrapassam o montante do recurso oriundo do FPM (Fundo de Participação dos Municípios). Municípios esses com base econômica mais sólida, atividades mais diversificadas que agregam mais valor ao bem ou produto (OLIVEIRA, 1998).

\subsection{VARIÁVEIS TRIBUTÁRIAS E ECONÔMICAS}

Para mensurar a influência de cada variável na grandeza da competência econômica dos Municípios Paranaenses, foram escolhidas aquelas que melhor estimam a ação tributária e econômica. Dada importância a variedade dos segmentos econômicos existentes no Estado do Paraná e também sobre o endividamento municipal e as despesas correntes, por analisar que estes forçam as administrações públicas á busca de eficácia na captação de receitas á proporção que aumentam suas despesas.

Destaca-se que os Municípios Paranaenses possuem grande diversidade de atividades econômicas regionais, discriminando entre si a formação de ganhos econômicos. Assim, podendo, constatar quais elementos existentes nos Municípios são efetivamente responsáveis pela maior ou menor dependência das transferências do Governo Federal e ou Estadual (ZANATTO, 2011).

\subsubsection{SETORES ECONÔMICOS}

O carro chefe, para maioria dos Municípios de pequeno porte, para fins de composição dos índices de participação dos Municípios é o ICMS (imposto sobre operações e circulação de mercadorias, prestação de serviços de transporte interestadual e intermunicipal e serviços de comunicação), já que os recursos municipais provêm das seguintes receitas: Agropecuária, Indústria, Comércio e Serviços (ZANATTO, 2011).

\section{1 - PRODUÇÃO AGROPECUÁRIA}

A Produção agropecuária é obtida pelo total da produção de uma região ou Município, sendo ela a produção vegetal, ou seja, extração, sementes, adubo orgânico, mudas de árvores, da produção animal e derivados, como laticínios, e de outras relacionadas com atividades agropastoris que porventura tenha o Município. Neste trabalho será analisado o Índice da Produção Agropecuária de cada município, independente de sua comercialização.

\begin{tabular}{|l|c|c|}
\hline PRODUTO & $\begin{array}{c}\text { QUANTIDADE } \\
\text { (toneladas) }\end{array}$ & $\begin{array}{c}\text { PARTICIPAÇÃO } \\
\text { PARANÁ/BRASIL (\%) }\end{array}$ \\
\hline Cana-de-açúcar & 44.907 .862 & 6,12 \\
\hline Milho & 12.472 .720 & 22,41 \\
\hline Soja & 15.457 .911 & 20,66 \\
\hline Trigo & 2.444 .995 & 42,97 \\
\hline Feijão & 815.280 & 23,73 \\
\hline
\end{tabular}

Tabela 1 - Principais Produtos Agrícolas Paraná - 2011

Fonte: Elaborado com dados extraídos IPARDES, IBGE (2011). 
O Paraná destaca-se como um dos maiores produtores nacional de grãos (IPARDES, 2011). Com grande diversidade de produtos, devido ao emprego de técnicas agronômicas inovadoras. Observando a tabela 01, destacam-se na composição dos produtos agrícolas local: a soja com $20,66 \%$ do total da produção do país, o milho com $22,41 \%$ do total da produção, o trigo com $42,97 \%$, o feijão com $23,73 \%$ e a cana-de-açúcar com $6,12 \%$ do total da produção do país. Estes produtos destacam-se na formação da estrutura produtiva da agricultura local. Emergindo com forte avanço a produção de frutas e de produtos orgânicos (IPARDES, 2011).

Quanto ao desempenho da pecuária, destaca-se a avicultura, com 25,2\% do total de abates do País. Já nos segmentos bovinos e suínos, a participação é de $4,1 \%$ e $18,7 \%$, respectivamente.

\section{2 - INDÚSTRIA}

A industrialização dos produtos agrega valor aos mesmos, tornando esse setor importante gerador de recursos para os Municípios. O Estado do Paraná apresenta Municípios com alta industrialização e outros principiantes e até mesmo completamente agrícolas. Municípios com maior industrialização contribuem positivamente nas bases tributárias, seja na tributação direta que recai sobre a atividade industrial, ou na tributação indireta, visto que, quando o setor da indústria de uma determinada região é consistente, traz consigo outras atividades oriundas da existência do setor industrial (ZANATTO, 2011).

A composição do valor da transformação industrial paranaense nos segmentos de bebidas e alimentos, refino de petróleo e veículos automotores, respondem por $54 \%$, os segmentos de papel e celulose, produtos químicos e maquinas e equipamentos respondem por $14,4 \%$ do valor da transformação e os restantes $31,0 \%$ aos demais segmentos. $\mathrm{O}$ valor da transformação industrial do Paraná atingiu R\$48,9 bilhões em 2009 (IPARDES, 2011).

O Setor Terciário está relacionado aos serviços prestados a terceiros para satisfazer determinadas necessidades. Quanto mais rico um país ou região maior é a atividade desse setor e seu grau de desenvolvimento (PERIS, 2003).

No setor de serviços paranaenses, o valor adicionado atingiu R\$ 106,7 bilhões em 2009, com maior ênfase dos ramos de comércio, atividades imobiliárias e administração pública (IPARDES, 2011).

\section{3 - PRODUÇÃO PRIMÁRIA}

A produção primária esta inclusa no setor da economia denominado de Setor Primário, visto que, seus produtos são comercializados "in natura", e não adicionam aos mesmos nem uma forma de industrialização. Englobam nesse setor todos os produtos de origem vegetal, animal, mineral. Com a variável Valor Adicionado dos Produtos Primários, deseja-se constatar qual a participação da agricultura na representação econômica dos Municípios. A produção agropecuária do Estado é bem diversificada, mas esse setor não agrega muito valor ao produto, visto que, sua produção é comercializada in natura (ZANATTO, 2011).

A competitividade desse setor muda a cada ano, à medida que vão se introduzindo novas técnicas de produção, novas tecnologias, novos processos de diversificação e viabilidade de novos canais e formas de transportes dessa produção, tornando o preço das mercadorias mais competitivo. A comercialização desta produção instituiu uma infraestrutura de armazenagem e transporte. A dependência fica nas mãos do Governo Federal, quanto aos rumos da política agrícola que favoreça a produção primária (PERIS, 2003).

O calculo do valor adicionado desta atividade é feito não se deduzindo os insumos utilizados, tratando do conceito de valor da produção primária comercializada, não incluindo a parte do autoconsumo.

\subsubsection{OBRIGAÇÕES MUNICIPAIS}

\section{1 - PASSIVO TOTAL}

Essa variável busca explicar o endividamento de cada Município, as prioridades dadas pelos governos para destinação dos recursos disponíveis. São divididas em Administração e Planejamento, Educação e Cultura, Habitação e Urbanismo, Saúde e Saneamento, Assistência e Previdência, Transporte, Legislativo, Agricultura, Defesa Nacional, Indústria, Comercio e Serviços, Trabalho e outras (RIANI, 1997).

O endividamento público é uma ferramenta indispensável para a divisão intertemporal ótima das políticas públicas. É através dele que o provimento dos bens públicos pode ser provisoriamente desagregado da arrecadação dos recursos para lhe fazer frente. Porem, para que o endividamento possa liquidar de forma apropriada seu papel, é necessário que o emitente empregue uma política fiscal sustentável (COSTA, 2009). 
São vários motivos que explicam o crescimento das dívidas dos governos estaduais e municipais no passado recente, dentre eles estão: os governos para elevar o bem-estar da população, acabam se endividando; a polarização política e a incerteza eleitoral podem motivar a acumulação de dívidas; os Estados têm incentivos a gastar além dos seus meios e a transferir o financiamento de seus déficits para o Governo Federal; o constante adiamento do ajuste fiscal no âmbito dos governos estaduais resulta do pacto dos estímulos do federalismo fiscal com a ausência de consenso para a distribuição dos gastos do ajuste (Ibid.).

\section{2 - DESPESAS CORRENTES}

Para Riani (1997), as despesas agregadas possibilitam uma analise macroeconômica do cômputo das administrações publicas. Entretanto, esses dados são pouco fundamentados e por esse motivo não tornam a analise detalhada. Fazendo-se necessário um tratamento dos gastos, tornando mais visíveis. Agrupando assim as despesas por categoria ou função.

As despesas correntes fazem parte das despesas por categorias, e estão associadas e possibilitam uma analise mais apurada dos gastos fixos do governo com a manutenção da maquina administrativa e de serviços do Estado. As despesas correntes respondem pelo maior percentual dos gastos totais dos municípios

Para Zanatto (2011), á medida que as despesas municipais aumentam o esforço no sentido de realizar arrecadação também tende a aumentar. Dado que uma redução nas despesas é um tanto quanto difícil, o setor público, em geral, tem como válvula de escape o correspondente aumento na tributação ou outras formas de receitas para fazer frente ás suas supostas maiores despesas.

\section{METODOLOGIA}

Para a realização do presente estudo, será usado o método quantitativo, que utiliza a quantificação na coleta de informações, bem como no tratamento delas através de técnicas estatísticas. Pelas suas particularidades, o método quantitativo é habitualmente empregado nos estudos que visam classificar e conhecer a relação entre variáveis e examinar a ligação de causalidade entre os eventos, visto que, permite uma margem de confiança quanto ás deduções (RICHARDSON, 1999).

Com referencia á técnica de pesquisa, empregou-se a empírico-analítica, que segundo Martins (2002, p. 34): "São abordagens que apresentam em comum a utilização de técnicas de coleta, tratamento e análise de dados marcadamente quantitativos. Privilegiam estudos práticos. Suas propostas têm caráter técnico, restaurador $\mathrm{e}$ incrementalista".

Os dados utilizados para calcular o IDTE (Índice de Desenvolvimento Tributário e Econômico), foram obtidos nos relatórios contábeis e financeiros do banco de dados da Secretaria do Tesouro Nacional (Finanças Brasil), do Resumo Gerencial do VAF ( valor adicionado fiscal) do banco de dados da Secretaria de Estado da Fazenda/Fundo de Participação dos Municípios (Sefa/FPM). O presente trabalho consiste em verificar quais as variáveis econômicas e tributárias, que melhor explicam a capacidade própria de recursos para os 399 Municípios Paranaenses, visando menor dependência dos repasses Federais e ou Estaduais, no período entre 2001 a 2010.

Tendo em vista a ausência de dados em determinados períodos, a amostra ficou reorganizada para 349 Municípios Paranaenses. Os municípios excluídos da amostra estão no anexo por ordem alfabética.

Neste estudo, aplicar-se a análise de dados em painel, que de acordo com Gujarati (2006), sobreveio da necessidade do uso da dimensão temporal e espacial de uma mesma unidade de corte transversal (uma Instituição, um Município, um País).

A aplicação dos dados em painel oferece algumas vantagens, sejam: amplia significativamente o tamanho amostral; os dados em painel são os mais apropriados para o estudo da dinâmica da mudança; possibilitam examinar normas comportamentais mais difíceis; os dados são os mais explicativos e efica: compensação, os dados em painel gera problemas de estimação e inferência. I problemas a serem enfrentados está a heterocedasticidade, a auto-correlação e a correlação cruzada de unidades individuais no mesmo ponto do tempo (Ibid.).

A regressão com dados em painel considera o seguinte modelo básico:

\footnotetext{
IDTE $_{\text {it }}=\beta_{1}+\beta_{2}$ VAFpa $_{2 i t}+\beta_{3} \mathrm{VAFi}_{3 i t}+$ $\beta_{4} \mathrm{VAFc}_{4 i t}+\beta_{5} \mathrm{VAFpp}_{5 i t}+\beta_{6} \mathrm{PASS}_{6 \mathrm{it}}+\beta_{7} \mathrm{DESPC}_{7 \mathrm{it}}$ $+\beta_{8} P_{0 P} P_{\text {it }}+u_{\text {it }}$

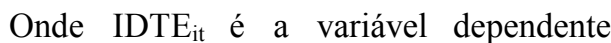
(Índice de Desempenho Tributário e Econômico); $\mathrm{VAFpa}_{2 \mathrm{it}}, \mathrm{VAFi}_{3 \mathrm{it}}, \mathrm{VAFc}_{4 \mathrm{it}}, \mathrm{VAFpp}, \mathrm{PASS}_{5 \mathrm{it}}, \mathrm{POP}_{6 \mathrm{it}}$ e $\operatorname{DESPC}_{7 \text { it }}$ são as variáveis independentes; $\beta_{1}$ é o parâmetro de intercepto; $\beta_{2}, \beta_{3}, \beta_{4}, \beta_{5}, \beta_{6}$ e $\beta_{7}$ são os coeficientes angulares; $i$ representa a i-ésima
} 
unidade de corte transversal; $t$ o t-ésimo período de tempo; $\mathrm{u}_{\mathrm{it}}$ termo de erro.

Dentre os modelos que ajustam o modelo geral a fim de torná-lo mais funcional, estão: FixedEffects Model (Efeitos Fixos) e o Random Effects (Efeitos Aleatórios). O Modelo de Efeitos Fixos baseia-se na premissa de que os coeficientes da regressão podem variar de indivíduo para indivíduo ou no tempo, ainda que permaneçam como variáveis fixas, ou seja, não aleatórias (MARQUES, 2000). Já o Modelo de Efeitos Aleatórios segue a premissa de que a influência do comportamento do indivíduo ou o efeito do tempo não podem ser conhecidos.

A escolha do modelo mais apropriado para a amostra em estudo acontece através da comparação realizada pelo Teste de Hausman, o qual verifica o modelo mais adequado para uso.

\section{ANÁLISES DOS RESULTADOS}

As análises de dados em painel foram feitas para efeitos fixos (EF) e efeitos aleatórios (EA), e a escolha do melhor modelo explicativo deu-se através do Teste Hausman. O qual considera duas hipóteses:
H0: $p$-valor $>0,05$ - o Modelo de Efeitos Aleatórios é consistente.

Ha: $p$-valor $<0,05$ - contraria a hipótese nula de que o Modelo de Efeitos Aleatórios é consistente, validando a hipótese alternativa da existência do Modelo de Efeitos Fixos.

Ao aplicar o primeiro modelo utilizando todas as variáveis (Produção Agropecuária, Valor Adicionado Fiscal (VAF) da Indústria, Valor Adicionado Fiscal (VAF) Comércio/Serviços, Valor Adicionado Fiscal (VAF) Produtos Primários, Passivo Total (PASS), Despesas Correntes (DESPC) e População (POP)) como variáveis explicativas do melhor desempenho tributário e econômico, observou-se que o resultado das regressões, com efeitos fixos e aleatórios, não apresentou significância, bem como as variáveis individualmente não apresentaram poder explicativo sobre a variável IDTE. Dessa forma, foi necessário fazer sucessivas exclusões de variáveis, até encontrar um modelo que fosse significativo e as variáveis individualmente apresentassem poder de explicação ao IDTE (Desempenho Tributário e Econômico).

Segue abaixo Tabela 2, a qual apresenta o teste de Hausman para o painel buscando explicar os objetivos do trabalho.

\begin{tabular}{|c|c|c|c|c|}
\hline & \multicolumn{2}{|c|}{ Coeficientes } & \multirow[b]{2}{*}{ (b-B) diferença } & \multirow{2}{*}{$\begin{array}{c}\text { sqrt(diag } \\
\left.\left(\mathrm{V} \_ \text {b-V_B }\right)\right)\end{array}$} \\
\hline & (b) fixo & (B) variável & & \\
\hline Passivo Total & $-1.56 \mathrm{e}-10$ & $-5.19 \mathrm{e}-10$ & $3.63 \mathrm{e} 10$ & $2.34 \mathrm{e}-11$ \\
\hline Despesas Correntes & $-1.30 \mathrm{e}-10$ & $-9.48 \mathrm{e}-11$ & $-3.55 \mathrm{e} 11$ & . \\
\hline VA Indústria & $-3.28 \mathrm{e} 11$ & $-2.49 \mathrm{e}-11$ & $-7.95 e-11$ & . \\
\hline VA Comércio/Serviços & $3.01 \mathrm{e}-11$ & $1.82 \mathrm{e}-13$ & $2.99 \mathrm{e}-11$ & - \\
\hline População & -0.000115 & $7.07 \mathrm{e} 06$ & -0.0000186 & $1.25 \mathrm{e}-06$ \\
\hline Prob $>$ chi $2=0,0000$ & & & & \\
\hline
\end{tabular}

Tabela 2 - Teste de Hausman para escolha do modelo mais apropriado para amostra

Fonte: Elaboração própria.

O teste Hausman apresentou um p-valor $<$ 0,05 (prob $>$ chi2 $=0.0000$ ), contrariando a hipótese nula que o modelo de Efeitos Aleatórios é consistente, validando a hipótese da existência do Modelo de Efeitos Fixos.

A Tabela 3 apresenta o resultado da regressão com efeitos fixos para o modelo.

\begin{tabular}{|l|c|c|c|c|c|}
\hline Variáveis & Coeficiente & Erro padrão & $\mathbf{t}$ & P>lt| & 95\% Conf. Intervalo \\
\hline Passivo Total & $-1.56 \mathrm{e}-10$ & $3.58 \mathrm{e}-11$ & -4.35 & 0.000 & $-2.26 \mathrm{e}-10-8.57 \mathrm{e}-11$ \\
\hline Despesas Correntes & $-1.30 \mathrm{e}-10$ & $5.02 \mathrm{e}-11$ & -2.60 & 0.009 & $-2.29 \mathrm{e}-10-3.20 \mathrm{e}-11$ \\
\hline VA Indústria & $-3.28 \mathrm{e} 11$ & $8.61 \mathrm{e}-12$ & -3.81 & 0.000 & $-4.97 \mathrm{e}-11-1.59 \mathrm{e}-11$ \\
\hline VA Comércio/Serviços & $3.01 \mathrm{e}-11$ & $1.22 \mathrm{e}-11$ & 2.46 & 0.014 & $6.14 \mathrm{e}-125.41 \mathrm{e}-11$ \\
\hline População & -0.000115 & $1.30 \mathrm{e}-06$ & -8.84 & 0,000 & $-0.000141-8.98 \mathrm{e}-06$ \\
\hline Constante & 1.264533 & .0338784 & 37.33 & 0,000 & 1.1981071 .330959 \\
\hline R-sq: within $=0,1184$ & Prob $>\mathrm{F}=0,0000$ \\
\hline
\end{tabular}

Tabela 3 - Regressão com efeitos fixos para o modelo

Fonte: Elaboração própria. 
Pelo resultado apresentado na Tabela 3, pode-se afirmar que o $\mathrm{R}$ do modelo de efeitos fixos, é de ordem de 11,84\%. Esse coeficiente apresenta modelagem adequada, visto que é habitual esses modelos de dados em painel apresentarem R baixos (FÁVERO et al.,2009). Quanto a significância, o modelo é significativo, pois mostra uma Prob $>\mathrm{F}<0,05$ (Prob $>\mathrm{F}=0,0000$ ).

Com fundamentação nos resultados alcançados para os coeficientes do modelo, pode-se afirmar que, das variáveis utilizadas para verificar quais melhor explicam o Desempenho Tributário e Econômico dos Municípios Paranaenses, a que apresentou relação positiva foi o VA Comércio/Serviços. Esse resultado demonstra o quanto é essencial o setor de comércio e serviços para o IDTE municipal. Deste modo, verifica-se que quando o VA do segmento de comércio/serviços dos Municípios Paranaenses aumenta em média 1\%, o IDTE aumenta em média $0,0000000000301 \%$ com as demais variáveis mantidas constantes. A existência desse segmento é que dá suporte para possibilitar a entrada de outras atividades econômicas, como agricultura, indústria, atividades turísticas dentre outras. $\mathrm{O}$ setor de serviços é o mais importante para a composição de melhores IDTE, mantendo a suposição inicial (ZANATTO, 2011).

$\mathrm{Na}$ análise da variável VA Indústria, encontrou-se uma relação negativa, ou seja, quando esse segmento aumenta em media 1\%, o IDTE reduz em média 0,000000000328\%. Isso pode ser explicado pelos Municípios Paranaenses serem em sua maioria (mais de $80 \%$ ) de pequeno porte e dependentes dos repasses oriundos do FPM, com indústrias pequenas ou até inexistentes. Outra possível explicação seria pelo modelo usar um grande período, no qual se passou por crises, como a de 2008 e diversos ajustes e incentivos fiscais, reduzindo assim a demanda e a arrecadação tributária.

A variável População também apresentou relação negativa com IDTE, o maior número de população esta diretamente ligada a uma economia mais desenvolvida e diversificada, municípios com população superior a 50.000 habitantes são os mais independentes dos repasses governamentais, no Paraná mais de $80 \%$ dos municípios caracterizamse pelo pequeno porte populacional e consequentemente com uma base tributária estreita (OLIVEIRA, 1998).

A hipótese inicial para a variável despesas correntes (DESPC) não foi confirmada pelo modelo, o que se esperava é que um aumento das despesas municipais causa uma maior busca por receitas que as compensem e com isso o IDTE tendesse ao aumento. Assim sendo, para o período analisado e atentando-se para as observações da amostra, quando aumentam às despesas correntes em média $1 \%$ o IDTE tende a reduzir em media $0,00000000130 \%$. Para a variável Passivo Total (PASS), a expectativa era de que seria próxima de zero, porém positiva, mantendo tudo o mais constante chegou-se a uma relação inversa. Dessa forma, quando o passivo total aumenta em média $1 \%$ o IDTE diminui em média $0,00000000156 \%$.

\section{CONSIDERAÇÕES FINAIS}

O presente estudo procurou analisar a eficiência dos Municípios Paranaenses na formação de receitas tributárias próprias limitando a sua dependência das transferências governamentais, bem como, verificar quais variáveis econômicas tem maior impacto sobre a arrecadação municipal e dos municípios com maiores IDTEs quais as características comuns entre eles. Para poder diagnosticar tais propostas foram desenvolvidas duas análises, primeiramente calculou-se o IDTE (Indicador de Desempenho Tributário e Econômico) dos Municípios Paranaenses e sua evolução no período 2001 á 2010.

Para esta análise constatou-se que os Municípios Paranaenses obtiveram evolução em alguns períodos em outras uma redução do desempenho, pode-se justificar a queda no período de 2007 e 2008 devido à crise financeira enfrentada, as diversas políticas econômicas e fiscais. Mostrando que o crescimento de suas receitas próprias não acontece de uma forma sustentável, além do que, crises que não são esperadas e enfraquecem esse desempenho (CNM, 2012).

Outrossim, a maioria dos Municípios apresentaram IDTE menor que 1, então: IDTE $<1$, Município com baixo nível de desempenho tributário e econômico, suas receitas mais significativas advêm das transferências FPM, não vinculadas a sua base econômica.

A análise seguinte foi com relação à quais variáveis interferem e melhoram o Desempenho Tributário e Econômico dos municípios no período de 2001 á 2010. Para a realização desse exercício foi utilizado o método de regressão com dados em painel. O método comprovou que o setor de comércio/serviços foi o segmento mais representativo na arrecadação dos Municípios Paranaenses, com o setor da Indústria e população apresentando relação inversa (negativa). O pequeno porte da maioria dos Municípios Paranaenses, dependentes da agricultura a qual não agrega valor aos produtos, pode ser uma das explicações para o 
segmento da indústria ser negativo e para a variável Produção Agropecuária e Produtos Primários não apresentarem significância.

Para a variável Produtos Primários, é importante salientar que mesmo não apresentando significância no modelo deve-se saber que favorece a arrecadação municipal de forma indireta, impulsionando os outros segmentos econômicos, como indústrias e setor de comércio e serviços.

Um ponto relevante refere-se ao fato de que quando aumentam as despesas correntes e o passivo total esperava-se um aumento no IDTE, mas essa hipótese inicial não foi confirmada, mostrando que os administradores municipais não se empenham na busca imediata de recursos que compensem suas despesas, reduzindo dessa maneira o IDTE.

Os maiores IDTEs foram encontrados nos municípios mais populosos os quais possuem maiores números de indústrias e prestadores de serviços, mas no cálculo estatístico essa variável apresentou coeficiente baixo $(-0,0000115)$, mas com significância. Não obtendo aumento do IDTE para os Municípios Paranaenses. Ressaltando que mais de $80 \%$ dos Municípios Paranaenses possuem população de até $15 \mathrm{mil}$ habitantes, com estrutura econômica frágil.

Por fim, ressaltasse a importância das transferências intergovernamentais, dado que a grande maioria dos Municípios Paranaenses é de pequeno porte e não teriam a suficiência de recursos próprios para prover a demanda por bens e serviços públicos. Porém, que essas transferências aconteçam e atinjam um montante ótimo, ou seja, um montante suficiente para fomentar uma maior independência e igualdade entre os municípios, mas sem com isso desmotivar a eficiência pública local, tanto em relação à cobrança de receitas próprias como relativo a fornecimento de serviços públicos.

A dificuldade de disponibilidade de dados para o período analisado e a falta de dados mais segmentados foram a principal dificuldade enfrentada. Buscou-se o valor do PIB por municípios e segmento da economia, na falta de disposição desses dados, procurou-se o que melhor se identificasse com o mesmo, no caso, valor adicionado por setor da economia. 


\section{REFERÊNCIAS}

BRASIL. (1988). Constituição Federal. Brasília: Senado Federal. Disponível em: $<$ http://www.planalto.gov.br/ccivil_03/Constituicao /Constituiçao.htm>. Acesso em: 9/06/2012.

CARVALHO JR. P.H.B. (2006). IPTU no Brasil: Progressividade, Arrecadação e Aspectos ExtraFiscais. Texto para discussão n. 1251, Brasília, dez/2006. Disponível em: $<$ http://desafios.ipea.gov.br/sites/000/2/publicacoes /tds/td_1251.pdf $>$. Acesso em: 30/04/2012.

CEPAM. Centro de Estudos e Pesquisas de Administração Municipal. (1997). O Município em Perguntas e Respostas. São Paulo: Malheiros Editores.

CNM. Confederação Nacional dos Municípios. (2012). Estudo sobre Cenário financeiro dos Municípios Brasileiros em final de mandato. Disponível em: $<$ http://www.cnm.org.br/images/stories/dev/files/C NM_Estudo_dificuldade_financeira_de_fim_de_m andato.pdf $>$. Acesso em: 30/09/2012.

COSTA. N. N. (1999). Curso de Direito Municipal Brasileiro. Rio de Janeiro: Forense.

COSTA, C. E. E. L. (2009). Sustentabilidade da dívida pública. Disponível em: $<$ http://www.tesouro.fazenda.gov.br/divida_publica /downloads/Parte\%201_ 3.pdf>. Acesso em: 27/05/2012.

EUSÉBIO, G. L. (2009). Estados e Municípios de pires na mão. Revista Desafios do Desenvolvimento, p. 34-38, Abril de 2009. Disponível em: <http://desafios2. ipea.gov.br/sites/000/17/edicoes/50/pdfs/rd50not03 .pdf>. Acesso em: 30/04/2012.

GASPARINI, C. E.; MELO,C. S. L. (2004). Equidade e Eficiência Municipal: uma avaliação do Fundo de Participação dos Municípios (FPM). Finanças Públicas: VIII Premio Tesouro Nacional, p. 337. Brasília: Universidade de Brasília.

GUJARATI, D. (2006). Econometria básica. 4. ed. Rio de Janeiro: Elsevier.

IPARDES. Instituto Paranaense de Desenvolvimento Econômico e Social. (2011). Paraná em Números. Disponível em: $<$ http://www.ipardes.gov.br/index.php?pg conteudo $=1 \&$ cod_conteudo $=1>$ Acesso em: $16 / 05 / 2012$.

MARTINS, G. A. (2002). Manual para elaboração de monografias e dissertações. 3. ed. São Paulo: Atlas.

OLIVEIRA, F. A. (1991). Autoritarismo e Crise Fiscal no Brasil. São Paulo: Hucitec.

OLIVEIRA, F. A.; FORTES, F. B. C. T. P.; ANDRADE. R. (1998). Receitas dos Municípios Mineiros: Diversidade e Indicadores. Finanças dos Municípios Mineiros: Diversidade de Indicadores. IX Seminário sobre Economia Mineira, p. 651-678. Disponível em:

http://www.cedeplar.ufmg.br/diamantina2000/2000 /FABRICIO.pdf $>$. Acesso em: 02/05/2012.

PERIS, A. F. (2003). Estratégias de Desenvolvimento Regional. 2. ed. Cascavel: Edunioeste.

REZENDE, F. A. (2001). Finanças Públicas. 2 ed. São Paulo: Atlas.

RIANI. F. (1986). Economia Setor Público. São Paulo: Atlas.

(1997). Economia do Setor Público. 3. ed. São Paulo: Atlas.

RICHARDSON, R. J. (1999). Pesquisa social: Métodos e técnicas. 3. ed. Atlas: São Paulo.

TORRES, R. L. (2003). Curso de Direito Financeiro e Tributário. 10. ed. atualizada. Rio de Janeiro: Renovar.

ZANATTO, N.; KROTH, D. C.; RODRIGUES, M. P. (2011). Desempenho fiscal Municípios catarinenses e seus determinantes: uma análise econométrica para o período de 2000 a 2008. Perspectiva Econômica, 7 (2), p. 78-92, jul/dez. 2011 